\title{
A COMPARISON OF MEMORY UNDER THREE METHODS OF ANAESTHESIA WITH NITROUS OXIDE AND CURARE
}

\author{
Harvey A. Taub and Louis Eisenberg*
}

A NUMBER OF RECENT REPORTs describing methods of "balanced" anaesthesia with the nitrous oxide-curare technique also suggest that, with these techniques, patients will have little or no recall of the operation..$^{1-4}$ One of the methods ${ }^{1,2}$ takes advantage of the known amnesic property of diazepam ${ }^{5,6}$ and combines this drug with morphine for both premedication and induction. However, other studies $^{3,4}$ have suggested that induction with thiopentone results in lack of recall without the need for any other adjuncts to nitrous oxide and curare. In fact, this method of anaesthesia has been described both with ${ }^{3}$ and without ${ }^{4}$ the use of morphine as a premedicant. Thus, these studies suggest that the nitrous oxide technique may be adequate with respect to memory even without the use of any narcotic or neuroleptic drug.

In view of these suggestions, the present investigation was designed to evaluate and compare recall using three different methods of balanced nitrous oxide-curare anaesthesia. Two of the methods did not use any neuroleptic drug but did utilize thiopentone for induction while the third made use of the tranquilizer diazepam in combination with morphine for both premedication and induction.

\section{METHOD}

\section{Patients}

The volunteer subjects were 63 patients ( 61 male, 2 female) who were scheduled to have general anaesthesia for elective operations and who met the criteria of having no hearing disabilities, psychiatric disorders, epilepsy, allergy to narcotics or history of prolonged use of alcohol or psychotropic drugs. Nineteen per cent were assigned American Society of Anesthesiologists physical status rating of $\mathrm{I}$, 71 per cent were rated as II, and 10 per cent rated as III. They ranged in age from 17 to 66 years (mean $(\bar{x})+44.3$ years) and had a mean body weight of 174.9 pounds $(79.3 \mathrm{~kg})$.

\section{Anaesthetic Procedures}

The three methods of "balanced" anaesthesia investigated in this study have been reported in detail elsewhere and only a short review of the salient points will be noted ( Table I).

1. Liverpool Protocol. ${ }^{4}$ No premedication was given. In the operating room, the intravenous administration of atropine 0.4 to $0.6 \mathrm{mg}$ was followed by an induc-

\footnotetext{
- Veterans Administration Hospital and State University of New York Upstate Medical Center, Syracuse, New York 13210, U.S.A.
} 
TAUB \& EISENBERG: MEMORY AND ANAESTHESIA

TABLE I

Summary of The ANaesthetic Methods

\begin{tabular}{|c|c|c|c|}
\hline & Liverpool & Roosevelt & Diazepam \\
\hline Premedication & Atropine IV & $\begin{array}{l}\text { Atropine IM } \\
\text { Morphine IM }\end{array}$ & $\begin{array}{l}\text { Atropine IM } \\
\text { Morphine IM } \\
\text { Diazepam IM }\end{array}$ \\
\hline Induction & $\begin{array}{l}\text { Thiopentone } \\
\mathrm{N}_{2} \mathrm{O} 75 \% \\
\text { Curare }\end{array}$ & $\begin{array}{l}\text { Thiopentone } \\
\mathrm{O}_{2} 100 \% \\
\text { Succinylcholine }\end{array}$ & $\begin{array}{l}\text { Diazepam } \\
\mathrm{N}_{2} \mathrm{O} 70 \% \\
\text { Succinylcholine } \\
\text { Morphine }\end{array}$ \\
\hline Maintenance & $\begin{array}{l}\text { Curare } \\
\mathrm{N}_{2} \mathrm{O} 71 \%\end{array}$ & $\begin{array}{l}\text { Curare } \\
\mathrm{N}_{2} \mathrm{O} 70 \%\end{array}$ & $\begin{array}{l}\text { Curare } \\
\mathrm{N}_{2} \mathrm{O} 63 \% \\
\text { Morphine }\end{array}$ \\
\hline Termination & $\begin{array}{l}\text { Atropine } \\
\text { Neostigmine }\end{array}$ & $\begin{array}{l}\text { Atropine } \\
\text { Neostigmine }\end{array}$ & $\begin{array}{l}\text { Atropine } \\
\text { Neostigmine } \\
\text { Naloxone }\end{array}$ \\
\hline
\end{tabular}

tion dose of thiopentone $(260 \mathrm{mg}$ ). Tubocurarine $(30$ to $45 \mathrm{mg}$ ) was then administered and manual hyperventilation was instituted using $6: 2 \mathrm{~L} / \mathrm{min}$ nitrous oxide-oxygen ( 75 per cent). Within approximately three to five minutes the trachea was intubed. Before the start of the operation $\mathrm{N}_{2} \mathrm{O}$ was reduced to 71 per cent $(5: 2 \mathrm{~L} / \mathrm{min})$ and mechanical ventilation was instituted. Incremental doses of tubocurarine were given as required. At the end of the operation curarization was reversed with atropine and neostigmine.

2. Roosevelt Protocol. ${ }^{3}$ Premedication was with morphine $10 \mathrm{mg}$ and atropine $0.4 \mathrm{mg}$. Thiopentone 4 to $8 \mathrm{mg} / \mathrm{kg}$ was given for induction in a dose sufficient to abolish the lid reflex. Following succinylcholine $1 \mathrm{mg} / \mathrm{kg} 100$ per cent oxygen was administered by face mask and intubation was performed. Maintenance was with 70 per cent nitrous oxide-oxygen $(3.5: 1.5 \mathrm{~L} / \mathrm{min})$ and controlled ventilation, with the ventilator set to deliver a minute volume of $90 \mathrm{mg} / \mathrm{kg}$ at a rate of 8 to 10 per minute. Tubocurarine $(0.3 \mathrm{mg} / \mathrm{kg})$ was administered and curarization was maintained by half that dose every half-hour according to a fixed dosage schedule. At the termination, the reversal of curare was accomplished with atropine and neostigmine.

3. Diazepam Protocol. ${ }^{1,2}$ Subjects were premedicated with diazepam 10 to 20 $\mathrm{mg}$, morphine sulfate 10 to $15 \mathrm{mg}$, and atropine 0.4 to $0.6 \mathrm{mg}$. Induction was with intravenous morphine 3 to $5 \mathrm{mg}$, diazepam 10 to $20 \mathrm{mg}$ and succinylcholine $100 \mathrm{mg}$ to facilitate intubation and 10 per cent $\mathrm{N}_{2} \mathrm{O}$ with $\mathrm{O}_{2}(7: 3 \mathrm{~L} / \mathrm{min})$. During maintenance the patients were ventilated mechanically and received $\mathrm{N}_{2} \mathrm{O} 63$ per cent 5:3 $\mathrm{L} / \mathrm{min}$ with supplemental curare and morphine. At the end of operation curare reversal was carried out routinely with atropine and neostigmine, and, where indicated, narcotic reversal was accomplished with naloxone.

Each patient was assigned in random fashion to receive anaesthesia by one of the three methods. Comparison of the three groups indicates that there were no statistical differences or trends with respect to body weight, age, or physical status of the patients. In addition, the operative procedures were similar across the groups (Table II) and there were no significant differences with respect to duration of the operations. The over-all mean operating time was 173.4 minutes. 
TABLE II

Surgical Procedures Performed

\begin{tabular}{lccc}
\hline \hline & Liverpool & Roosevelt & Diazepam \\
\hline Inguinal Hernia & 2 & & 2 \\
Intra-Abdominal & 6 & 5 & 7 \\
Chest & 1 & 1 & 6 \\
Orthopedic & 8 & 5 & 1 \\
Head-Neck & & 1 & 2 \\
Neurosurgical & 2 & 3 & 1 \\
Dental & 1 & 1 & 1 \\
Urological & 1 & 1 & 21 \\
Peripheral Vein Procedure & 21 & 21 & \\
$\quad$ Total & &
\end{tabular}

\section{Memory Training Procedures}

The stimulus materials and testing procedures were identical to those described in detail in a previous study. ${ }^{2}$

Stimuli. The stimuli were four word-pairs and three narrative passages which were taped and presented through headphones. The word-pairs were to evaluate the induction period and, in general, were presented 4 minutes (word-pair \#1) and 1 minute (word-pair \#2) before, and again $\frac{1 / 2}{2}$ minute (word-pair \#3) and $3 \frac{1}{2}$ minutes (word-pair \#4) after the beginning of induction. The three narrative passages were used to evaluate the surgical period and were exhibited at the time of incision, during the period of maintenance, and at lightening of anaesthesia respectively. Four different stimulus tapes were constructed to compensate for the possibility of bias.

Instructions and Procedures. One investigator interviewed all volunteer patients on the day before operation and provided instructions about the study. On the day of operation another investigator rated the state of the patient's preoperative sedation on a 7-point alertness scale, observed and timed the surgical events and, using a randomly assigned tape, presented the words and passages at the appropriate times. A nurse interviewed the patients in the recovery room to determine if they knew where they were, why they were there and whether they were aware of the date. The nurse also informed them of the time of day, and rated them for alertness using the same scale that had been applied preoperatively. The same investigator who had interviewed the subject on the day before operation, and who had no knowledge of the group or tape assignments, interviewed and tested all patients after the operation, usually within two days $(\bar{x}=1.7$ days $)$. Patients were asked to recall all they could from the time they left the ward until they awoke after the operation. In addition, recognition was evaluated using a composite tape which, for each patient, consisted of their stimulus materials intermixed with eight additional word-pairs and six additional narrative passages. The patient had to indicate if he recognized any word-pair or passage as one played in the operating room.

\section{REsUlts}

\section{Pre-and Post-Induction Events}

All patients were awake upon entering the operating room and were rated as 
TABLE III

Frequency of Pre-Induction Alertness Ratings for Each Group $(\mathrm{N}=21)$

\begin{tabular}{cccc}
\hline \hline Rating & Liverpool & Roosevelt & Diazepam \\
\hline 1 & 21 & 8 & 8 \\
2 & 0 & 5 & 9 \\
3 & 0 & 8 & 4 \\
\hline
\end{tabular}

either 1 (Alert), 2 (Alert but sedated), or 3 (Drowsy). Analysis of the frequency of these ratings (Table III) indicate group differences ( $x^{2}=25.8, d f=4, p<0.01$ ) probably related to the use of premedication in the Roosevelt and Diazepam protocols. Patients in these groups were similar, and were rated as less alert than those in the unpremedicated Liverpool group. However, premedication did not appear to affect memory of the preinduction events and none of the measurements suggested any statistical differences or trends in group comparisons. More than 90 per cent of the patients recalled the pre-induction events which, on the average, occurred between 10 and 20 minutes before induction (i.e., arrival in the operating room, transfer to the table, placement of earphones, placement of intravenous infusion and ground plate). Further, at least one of the two word-pairs that were presented 4 minutes and 1 minute before induction was recalled by more than 80 per cent and recognized by approximately 90 per cent of the patients in each group.

Analyses of the immediate post-induction events indicated that only one to two patients in each group recalled word-pair \#3 and although this stimulus was recognized by more patients in the Diazepam (7) than in Liverpool (2) or Roosevelt groups (4), the differences did not approach significance $(p>0.10)$. A number of patients (4 Liverpool, 5 Roosevelt and 2 Diazepam) also recalled the anaesthesia mask which generally was placed within 2 minutes of induction. Word-pair \#4 which was exhibited $3 \frac{1}{2}$ minutes after induction was not recalled by any of the patients, and recognition of this stimulus was at chance levels for all groups (5-11 per cent). Finally, tracheal intubation, which was done approximately 5 minutes $(\bar{x}+5.1$ minutes) after induction, was recalled by only one patient. This patient from the Roosevelt group reported hearing conversations before falling asleep, including "OK, he's out now." He further stated that he attempted to show that he was still awake but was unable to move. Although he fell asleep soon afterwards, he described the incident as very frightening, and had recurring vivid nightmares during the first three or four days following the operation.

\section{Surgical events}

None of the patients recalled any of the narrative passages and, further, the frequency of correct recognition responses of all groups was at the same chance levels as the correct guesses for the paragraphs not presented in the operating room (15-30 per cent). However, three patients (1 Liverpool and 2 Roosevelt) recalled some portion of the surgical experience. These memories were vague and, in general, appeared to be of events that occurred toward the end of the operation. All three reported feeling pressure without pain with specific comments being that the pressure in the abdomen was "quick" or "sharp" and occurred during a 
TABLE IV

RECOVERY RoOM RESULTS INCLUdING:

1. Frequency of Correct Responses to Orientation Questions

2. Frequency at Each Alertness Rating and

3. FREQUENCY OF RECALl OF RECOVERY ROOM EVENTS (n $=21$ )

\begin{tabular}{lccc}
\hline \multicolumn{1}{c}{ Measurement } & Liverpool & Roosevelt & Diazepam \\
\hline 1. Orientation Questions & & & \\
Why, Where, Month, Year & 20 & 21 & 21 \\
2. Alertness Ratings & & & \\
Alert & 14 & 11 & 8 \\
Drowsy & 4 & 1 & 6 \\
Sleepy & 3 & & \\
3. Recall of Events & & 8 & 3 \\
Extubation & 9 & 20 & 13 \\
Any conversation with nurse & 19 & 16 & 6 \\
Interviewed by nurse & 13 & 11 & 6 \\
\hline Time told & 12 & & \\
\hline
\end{tabular}

period of unknown conversation (Liverpool Group - Inguinal Herniorrhaphy); that there was a "rapping" on his back, unknown background conversations and clipping sounds (Roosevelt Group - Lumbar Laminectomy); and one patient felt air being forced in and out of his mouth, a pulling and pressure on his back and conversation including "There, he's done and ready to go" (Roosevelt Group Lumbar Laminectomy). This latter patient also reported that he was fearful and attempted, unsuccessfully, to open his eyes and to speak. Neither of the other patients expressed fear although one (Roosevelt Group) reported a "strange" dream about running and getting separated from his wife.

\section{Recovery Room Events}

The groups did not differ $(F<1)$ with respect to the amount of time spent in the recovery room $(\bar{x}+137.6$ minutes $)$. Patients in all groups were well-oriented when interviewed and knew where they were, why they were there, and the month and year (Table IV). However, Table IV and the analyses suggest that while the Liverpool and Roosevelt protocols led to recovery-room experiences and memories that were similar to each other, those in the Diazepam protocol were different. There was a trend towards differences in the frequency distributions of the recovery room alertness ratings $\left(x^{2}=8.1, d f=4, p<0.10\right)$ with patients on the Diazepam protocol being rated as less alert than patients in other groups. The test interviews held one or two days postoperatively also indicated significant group differences in recall that a nurse had had conversation with them in the recovery room $(x=9.5, d f=2, p<0.01)$ or had interviewed them $\left(x^{2}=10.2\right.$, $d f=2, p<0.01)$. In both cases, fewer patients in the Diazepam group recalled these conversations than in the other groups. The differences in recall of other events were not statistically significant, although comparisons of the Diazepam Group with the combined Liverpool and Roosevelt groups revealed statistical trends $(p<0.10)$ for both recall of extubation and time of day. In general, the qualitative statements of the patients also suggested that while numerous details were not recalled, patients in the Liverpool and Roosevelt groups had more vivid memories of their recovery-room experience. 
Although the frequency of dreaming during recovery did not differ as a function of Groups ( 3 Liverpool, 5 Roosevelt and 3 Diazepam), all of the Diazepam dreams were neutral and non-frightening while two in the Liverpool group and three from from the Roosevelt group were described as frightening, strange or death-related. Two of the Roosevelt dreams have been noted previously and appeared to be related to being awake during the induction or surgical period while the third concerned the patient's inability to get out of a locked room. The two Liverpool patients described extremely frightening dreams in which they believed they were dying. In both cases these dreams occurred more than once in the recovery room and again on the night following the operation. Finally one Liverpool patient noted that he had experienced the same frightening dream 10 years previously following an ether anaesthetic.

\section{Clinical Comparisons}

Hiccups. In the Roosevelt group, one patient experienced hiccups during intubation, while a second developed hiccups during operation. He also was perspiring at the same time, indicating, perhaps, that analgesia was inadequate.

Nausea and Vomiting. Two patients in each of the Liverpool and Roosevelt groups experienced nausea during the recovery period and one of them vomited (Liverpool).

Curare Dosage. Although the mean duration of operations was similar for all groups $(\overline{\mathrm{x}}=173$ minutes $)$, there were statistically significant differences $(F=$ $8.5, d f=2,60, p<0.02)$ in the mean total dosage of curare administered $(71.7 \mathrm{mg}$ for Liverpool, $63.0 \mathrm{mg}$ for Roosevelt, $51.4 \mathrm{mg}$ for Diazepam). Similarly there were significant differences $(F=6.9, d f=2,60, p<0.01)$ in the mean amount of neostigmine required for complete reversal of curare $(3.6 \mathrm{mg}$ for Liverpool, $2.9 \mathrm{mg}$ for Roosevelt and $2.6 \mathrm{mg}$ for Diazepam).

Postoperative Pain. The frequency of complaints of severe pain could not be evaluated statistically ( 7 Liverpool, 6 Roosevelt, 4 Diazepam) because of the small number of subjects involved. It is to be noted, however, that one patient in the Liverpool group, who complained of both nausea and severe pain, became extremely depressed. He stated repeatedly during the recovery period that he felt he was going to die. When interviewed the following day, he refused to discuss the recovery-room experience and abruptly terminated the interview.

\section{Discussion}

In agreement with previously published reports, ${ }^{1-4}$ the results suggest that these three variations in the nitrous oxide-curare technique are successful in producing anaesthesia and that patients have no recall of the major portion of the surgical procedure. That is, even though the plane of anaesthesia produced is light, these methods of "balanced" anaesthesia appear to block all memory of the operation except for some events near the end of, or immediately following it. The present study indicates that one Liverpool and two Roosevelt patients had some recall of this late portion of the surgical experience. While none of the present Diazepam patients had any such recall, the previous study of 60 patients ${ }^{2}$ reported that five 
had vague memory of events immediately following the operation (e.g. pharyngeal suctioning, trimming of a cast, removal of an adherent Vi-Drape ${ }^{\circledR}$ ).

The major differences among the groups appeared in the post-operative period and seemed to be between the Diazepam and each of the other two protocols. First, groups differences were observed in the quality of the emotional responses associated with post-operative recall of the surgical experience. Most importantly, none of the Diazepam patients, in this or in the previous studies, indicated that any recollections of events were emotionally disturbing or unpleasant. On the other hand, one patient in each of the other two groups described his experiences as frightening, and an additional Liverpool patient was extremely depressed in the recovery room and was sure he was dying. Second, while none of the present or previous Diazepam patients reported nightmares or upsetting dreams, two of the Liverpool and three of the Roosevelt patients reported strange, frightening, or death-related dreams. This problem of nightmares had been previously reported with the Liverpool method. ${ }^{4}$ Finally, while all patients were well-oriented in the recovery room, those in the Diazepam group were more tranquil, exhibited less nausea and had less recall of the recovery-room experience than patients in either of the other two groups. Thus, the use of diazepam and morphine as adjuncts to the nitrous oxide-curare technique would appear to reduce both the incidence of noxious psychological reactions and the possibility of severe emotional trauma. Presumably, these effects may be attributed directly to the benzodiazepine tranquilizer, diazepam, which has psychosedative ${ }^{\mathbf{T}}$ and amnesic properties. ${ }^{\mathbf{5 . 6}}$ Indeed, $\mathrm{McClish}^{8}$ administered diazepam in the recovery area following open-heart operations and noted a marked reduction in the incidence of psychiatric reactions.

Other findings indicate that there were group differences in the total dose of curare administered for optimal surgical relaxation. The largest doses were required for the Liverpool patients, presumably because this protocol did not make use of either a narcotic or a tranquilizer, and left no option other than the administration of curare in response to the signs of both inadequate analgesia and relaxation. Consequently, large doses of neostigmine were also required for complete reversal of curare. Indeed, Brice, Hetherington and Utting ${ }^{4}$ routinely administered $5 \mathrm{mg}$ of neostigmine, a dose double the one usually recommended for clinical use. ${ }^{9}$ The Roosevelt protocol, utilizing morphine for premedication and a decreasing schedule for curare dosage, required less curare than the Liverpool protocol. Finally, the Diazepam protocol required the least amount of curare. This may have been due, in part, to a possible potentiating effect of diazepam upon the action of curare, ${ }^{7,10}$ although this effect has not been reported consistently. ${ }^{11-13}$ It is more likely that the decreased total dose of curare was due to the concomitant use of morphine. Since some of the clinical signs of inadequate analgesia include purposeful movements of head and arms, their occurrence would indicate the necessity for administering a narcotic-analgesic rather than a muscle relaxant. The advisability of adding a narcotic analgesic to "balanced" anaesthesia is not a new concept since as early as 1947 , Neff, et al., ${ }^{14}$ in discussing the problems of nitrous oxide anaesthesia, stressed the importance of using a narcotic to insure adequate pain relief before curare is administered. 


\section{SUMMARY}

Sixty-three volunteer patients participated in an investigation designed to evaluate memory of the surgical experience with three different methods of balanced nitrous oxide-curare anaesthesia. Two of the methods (Liverpool and Roosevelt protocols) used thiopentone for induction but did not utilize any neuroleptic drug, while the third (Diazepam protocol) used the tranquilizer diazepam in combination with morphine for both premedication and induction. In general, the results suggest that all three variations are successful in producing anaesthesia and that patients have no recall of the major portion of the surgical procedure. The major differences among the groups were exhibited in the post-operative periods. These findings suggest that diazepam affects the emotional quality associated with memory and thus aids the patients by reducing both the incidence of noxious psychological reactions and the possibility of severe emotional trauma. Finally, the findings also suggest the importance of using a narcotic analgesic as part of nitrous oxidecurare anaesthesia.

\section{RÉSUMÉ}

On a comparé le degré de souvenir de l'expérience chirurgicale chez soixante trois opérés volontaires anesthésiés avec l'une de trois variations de la technique d'anesthésie balancée au Protoxyde d'Azote-Curare.

Chez les opérés des deux premiers groupes (Protocole Liverpool et Protocole Roosevelt) l'induction a été faite au moyen de Thiopentone, alors que chez ceux du troisième groupe (Protocole Diazepam) on a utilisé le Diazepam et un narcotique pour la prémédication et pour l'induction.

Les observations de ces patients suggèrent que les trois variations de la méthode produisent de fait une anesthésie et que les malades ne gardent pas de souvenirs de la majeure partie de l'intervention.

Les différences notées se sont surtout manifestées au cours de la période postopératoire. Elles semblent indiquer que le Diazepam a une influence positive sur la qualité des souvenirs et ainsi, contribue à diminuer l'incidence de réactions psychologiques nocives et la possibilité de traumatisme émotonnel grave.

Enfin les observations semblent indiquer qu'il est important d'ajouter un narcotique analgésique à la technique d’anesthésie au Protoxyde-Curare.

\section{ACKNOWLEDGMENT}

The authors gratefully acknowledge Ms. M.T. Baker and Mr. G. Kline of the Psychology Service, Syracuse Veterans Administration Hospital for their technical assistance.

\section{REFERENCES}

1. Eisenberg, L. \& Kwan, A.M. Neumleptanaesthesia with diazepam-morphine in poor-risk surgical patients. Canadian Anaesthetists' Society Journal. 18: 465 (1971).

2. Eisenberg, L., Taub, H.A., \& Burana, A. Memory under diazepam-morphine neuroleptanesthesia in male surgical patients. Anesthesia and Analgesia - Current Researches. 53: 488 (1974). 
3. KeENAN, R.L. Nitrous oxide-curare anesthesia: Reappraisal. MCV Quarterly. 8: 142 (1972).

4. Brice, D.C., Hetherington, R.R., \& Utting, J.E. A simple study of awareness and dreaming during anaesthesia. British Journal of Anaesthesia 42: 535 (1970).

5. Frumin, M.J., Herekar, V., \& Jarvik, M.E. The amnesic action of diazepam, scopolamine and narcotics in preanesthetic medication. Presented at the International Congress of Pharmacology, Basle, 1969. Pp. 289-290.

6. Clarke, P.R.F., Eccersley, P.S., Frisby, J.P., \& Thornton, J.A. The amnesic effect of diazepam (valium). British Journal of Anaesthesia 42: 690 (1970).

7. Wulfsohn, N.L. The benzodiazepines. In Pharmacology of Adjuvant Drugs (ed. Howard, L. ), F.A. Davis, Philadelphia, Pp. 208-232 (1973).

8. McClish, A., Andrew, D., \& Tetreault, L. Intravenous diazepam for psychiatric reactions following open-heart surgery. Canadian Anaesthetists' Society Journal. 15: 63 (1968).

9. Wylie, W.D. \& Churchill-Davidson, H.C. A practice of anaesthesia, 3rd edition, Chicago: Year Book Medical Publishers (1972).

10. Stovner, J. Endresen, R. Intravenous anaesthesia with diazepam. Acta Anaesthesia Scandinavia 24: 223 (1966).

11. Dechêne, J. \& Desnosiens, R. Diazepam in pulmonary surgery. Canadian Anaesthetists' Society Journal 16: 162 (1969).

12. Hunter, A.R. Diazepam (valium) as a muscle relaxant during general anaesthesia: A pilot study. British Journal of Anaesthesia 39: 633 (1967).

13. McClish, A. Diazepam as an intravenous induction agent for general anaesthesia. Canadian Anaesthetists' Society Journal 13: 562 (1966).

14. Neff, W., Mayer, E.C., \& de la Luz Perales, M. Nitrous oxide and oxygen anesthesia with curare relaxation. California Medicine 66: 67 (1947). 